NBER WORKING PAPER SERIES

\author{
TAXATION AND THE EX-DIVIDEND DAY BEHAVIOR \\ OF COMMON STOCK PRICES \\ Jerry Green \\ Working Paper No. 496
}

NATIONAL BUREAU OF ECONOMIC RESEARCH

1050 Massachusetts Avenue

Cambridge MA 02138

July 1980

\begin{abstract}
This research was supported by National Science Foundation grants APR 77-06999 and SOC 78-06162. The author is grateful to Robert L. Stern for performing the computations and Martin Feldstein, Zvi Griliches and Lawrence Summers for helpful advice. The research reported here is part of the NBER's research program in Economic Fluctuations. Any opinions expressed are those of the author and not those of the National Bureau of Economic Research.
\end{abstract}




\section{Taxation and the Ex-Dividend Day Behavior of Common Stock Prices}

\section{$\underline{\text { ABSTRACT }}$}

The behavior of stock prices around ex-dividend days has been suggested as evidence for tax-induced clientele effects and as a means to estimate the average effective tax rate faced by investors. In this paper these possibllities are examined theoretically and empirically. Theoretically it is shown that the measured price drop per dollar of dividend may provide a biased estimate of the effective tax rate. Looking at the volume of trade around ex-dividend days we show that the conditions under which it would be unblased are unlikely to hold. Strong evidence, based on a broader data base than that used by previous investigators, is presented for the presence of the clientele effect. 


\section{Introduction}

This paper examines the behavior of common stock prices around exdividend days. There are two basic questions on which this evidence might be brought to bear: What is the market's valuation of capital within a firm? Is this valuation systematically related to the mixture of investors who own the firm's equity? In particular, is there a tendency for investors in lower tax brackets to hold shares in companies with high dividend payout rates, and, if so, is capital invested in such firms valued on the margin above that in low payout companies?

At first glance, measuring the average fall in the price of a stock per dollar of dividend paid would seem to be the perfect econometric experiment to determine the value of a dollar retained in the corporation relative to a dollar of investors' after tax personal income. Dividends are announced approximately two weeks before the ex-dividend date, and payment is made at a specified time, usually about one week later. Information relevant to the corporation's financial position is often made public at the same time the dividend is announced, but the intervening time should surely be sufficient for the market to incorporate it into the asset's price. Therefore, shortly before and after the ex-dividend day, the corporation is, on average, identical in all respects except the cash commitment necessary to pay stockholders. The change in its market price at that date should reflect, on average, the investors' valuation of this cash.

In a world where all investors are identical in their tax status, one-day risks can be neglected and transaction costs are absent, the price of the stock should fall by $(1-\theta)(1-c)$ dollars for every dollar of divi- 
dend, ${ }^{*}$ where $\theta$ is the marginal tax rate on dividend income and $c$ is the effective marginal rate on capital gains. If there were a systematic tendency for any larger fall, sure profits could be made by selling the stock on the day before it goes ex-dividend and buying the day after.

Dropping the homogeneity of tax rates while mafntaining all of the other assumptions immediately creates difficulties. Applying the arbitrage argument above separately to investors of each tax status we can see that no equilibrium could exist. Whatever is the expected fall in the price of the stock per dollar dividend, some tax category of investor will have a profitable arbitrage possibility. It is therefore necessary to re-examine the basic trading mechanism that produces this type of result.

We note that the potential arbitrage profit is unlikely to enable investors to overcome the transaction costs involved in the "roundtrip". Suppose, for example, that $\theta=.5$ and $c=0$, but that the stock falls by a full dollar per dollar of dividend. The profit that could then be made by selling the stock and repurchasing it after the dividend was paid would be one half of the dividend yield. This represents a good upper bound on the potential for speculative profit since the price fall must be between the lowest $1-\theta / 1-c$ faced by any investor and unity. Consider a stock paying dividends at a $10 \%$ annual rate. Payments being made quarterly, the profit potential is bounded by $1.25 \%$. As a "round-trip" (buy and sel1) transaction is required, it can be seen that even for the largest investors the transaction and administrative costs involved make it a poor venture. ${ }^{* *}$ Moreover, we

*

See Auerbach (1979), Bradford (1979) and King (1977). Note that we are, in principal, discussing "marginal q", not "average q." No attempt will be made to study the level of stock prices, see Bradford and Gordon (1979). **

Professional traders and large investors with low transaction costs would make a profit in this way. However tax rules governing "wash sales" and special provisions for profits on the accounts of traders make $\theta$ and $c$ approximately equal, reducing the profit potential even further. Our data on the pattern of volume around ex-dividend days (Section 6) suggests that short term arbitrage of this type does not occur. 
nave taken a rather extreme case here. If the fall in the price of the stock is half-way between the lowest value of $1-\theta / 1-c$ for any tax category and unity, the maximum profit potential would be further cut in half.

To summarizc, it seems unlikely that the arbitrage potential around ex-dividend days can be large enough to make a significant number of investors engage in such transactions on a regular basis. We are thereby freed from the paradoxes attending the non-existence of an equilibrium pattern of prices. However, we are likewise left at a loss to explain these price movements in terms of dividends and taxes. Worst of all, the absence of arbitrage may preclude the possibility of using the price pattern to infer market valuations of corporate capital. The extent to which such a methodology survives in a world of heterogeneous investors is a principal theme of this paper.

Previous writers* investigating this question were aware of the difficulties I have just pointed out. They argued, however, that roundtrip trading is not necessary for arbitrage to be effective. Investors who are planning to buy or sell the security close to the ex-dividend date may alter the timing of these transactions because of tax considerations. However the economic decision to adjust the trading date was not modeled in any detail. Being primarily empirical, these papers concentrated on careful statistical methodology, correcting for a variety of biases in the data.**

The most explicit paper on these points is Kalay (1978). Black and Scholes (1973) also seem to have a scenario like this in mind. $* \star$

These include roundoff problems due to stock prices being quoted in discrete jumps of $12.5 \mathrm{c}$, differences between opening and closing prices, correction for market closing implicit price ex-dividend, and the discrepancy between postfollowing day. Portfolio theory and the observed opening price the these authors with a theoretical and the capital asset pricing model provide that should correspond to the securities into strata rates. 
Our approach will be a rather different one. We will model the dynamics of investors timing decisions explicitly. Based on this structure we will derive the equilibrium behavior of prices on, and around, the ex-dividend day.

We will show that the measured price drop per dollar of dividend is, under some special assumptions, an unbiased estimator of the average effective tax rate facing the investors. However, if these assumptions are not satisfied, a variety of possible biases are present.

We then present two empirical analyses that bear on this issue. First, we show that the evidence for the clientele effect is strong. We estimate that averaged over all companies a dollar of dividends is worth 70 cents. However, this valuation varies strongly according to the companies' dividend yields. A one standard deviation increase in dividend yield raises the valuation to 80 cents. In a world composed of investors taxed at either $70 \%$ or zero these valuations translate into a dividend-induced shift from $42 \%$ to $28 \%$ taxable share owners.

In the second empirical analysis we challenge the assumptions of the model by looking for corroborative evidence on the pattern of trading volume. The conclusions reached are rather negative. Companies display widely divergent volume behavior near the ex-dividend date. This raises the possibility that the tax composition of traders on those days differs markedly from what it is at other times, and also from the composition of share owners. Estimation results based on ata pooled across compañes may be biased.*

We conclude that although a dividend-induced clientele effect is present, the average effective tax rates of the owners cannot be accurately estimated using the behavior of prices near ex-dividend days as evidence.

* Using only one company will not give us enough information to generate accurate parameter estimates. However, see Durand and May (1960) who find that for AT\&T stock the price drop is statistically not significantly different from the dividend, during the period 1948-1959. 


\section{A Two-Level Decision Process for Share Trading}

In light of the discussion above, we hypothesize that the pattern of stock prices around ex-dividend days arises from investors having a twoleve1 decision process as follows: First, the decision is made to acquire or sell a stock. This is unrelated to the timing of payments of dividends. Then, the actual execution of the transaction may be shifted over time so that the stock is or is not held at the dividend record date.

One can Imagine that in the absence of dividend-related considerations there would be an optimal time to undertake the transaction. For example, a sale to finance acquisition of another asset would be made at the date that would minimize the expenses on transaction costs, including forgone interest. If the motivation for the investor's decision is his perception of information that has not yet (he believes) been fully incorporated in the price of the security, then the optimal trading date is "as soon as possible." Whatever the circumstances that cause the desire to trade, the value of executing the transaction is likely to decline if it is delayed. On the other hand, liquidity considerations may make acceleration of trades, particularly purchases, more costly than executing them at what otherwise would be the optimal trading date. Costs of delay and acceleration will be a key ingredlent in our analysis of the behavior of stock prices around ex-dividend day

Let us suppose that the optimal transaction dates for the population of investors are uniformly distributed over time, and that the level of the stock's price is such that the number of orders to buy would be equal to se11-orders on average. In the absence of any dividend - or tax-related considerations the price of the stock would fluctuate without any predictable dynamic pattern. Of course new information or changing conditions in related 
asset markets would induce continual fluctuations. Moreover, on any one market day, the actual number of buyers might be different than the number of sellers simply because the numbers involved are not very large, even for rather heavily traded securities. Nevertheless, the absence of any systematic pattern in stock prices would not alter the uniformity of the arrival rates of orders to trade.

The situation becomes more complex when dividends and taxes are considered. Let us define a price pattern around an ex-dividend date to be an equilibrium if it induces a pattern of arrival rates for buy-orders over time that matches the arrival rates for se11-orders on a day-by-day basis. One should note that there is no requirement for these arrival rates to be constant over time. Their common fluctuations in equilibrium will induce a pattern of daily trading volume. Volume data are thus useful for a test of this model and for the interpretation of its conclusions regarding clientele effects.

It is important to point out that the equality of arrival rates for buy and sell orders does not imply that these rates are the same for every tax category of investor. Those in one situation may, for example be postponing some of their sales, while others may be postponing purchases. At another point in time their roles might be reversed.

We will now go on to a presentation of two models, admittedly great oversimplifications of reality, in which the equilibrium pattern of stock prices and trading volume are derived based on the considerations mentioned above. These models will then serve as the backdrop against which the empirical parts of the paper can be viewed. 


\section{Structure of the Mode1}

\section{$\underline{\text { Investors and Trades }}$}

There are two tax categories of investors, the taxed group called A and the untaxed group, called B. A's pay dividend and capital gains taxes. Let $(1-\bar{\theta})$ by the ratio of the net of tax value of $\$ 1$ of dividends to the net of tax value of $\$ 1$ of capital gains. The investors occasionally desire to trade securities on the market. Orders for such trades arrive at random. We distinguish four types of orders according to the identity of the trader, $A$ or $B$, and according to the direction of trade, buy or sell. To have a symbolic notation for the latter distinction we write + for buying and for selling. The arrival rates that would arise in the absence of tax or dividend considerations are thus denoted

$$
\lambda_{\mathrm{A}+}, \lambda_{\mathrm{A}-}, \lambda_{\mathrm{B}+}, \lambda_{\mathrm{B}-}
$$

for the four groups respectively. Because we imagine that the composition of investors who own the security is changing very slowly if at all, it is natural to assume that

$$
\lambda_{\mathrm{A}+}=\lambda_{\mathrm{A}-}
$$

(1)

$$
\lambda_{\mathrm{B}+}=\lambda_{\mathrm{B}-}
$$

$\underline{\text { Time }}$

Time is described by a discrete sequence of periods denoted by $t=\ldots,-2,-1,0,+1,+2, \ldots$. The date at which dividends are no longer paid to new owners of the security is called the ex-dividend date and is 
associated with $t=0$. Thus the last date at which a new owner is entitled to the dividend is $t=-1$; and the day before that is $t=-2$, etc.

\section{Costs of Distorted Trading Dates}

As discussed in the last section, a principal determinant of the equilibrium pattern of expected prices around the ex-dividend day is the cost of trading at a date other than that which would be the individual's optimum. These costs will be denoted by a function $g(s)$ where s measures the deviation from the optimal trade date. The variable $s$ is positive if trade is delayed until after the optimum and negative if trade is accelerated.

Without loss of generality we can take $\mathrm{g}(0)=0$. If $\left|\mathrm{s}_{1}\right|<\left|\mathrm{s}_{2}\right|$, then $0 \leqq \mathrm{~g}\left(\mathrm{~s}_{1}\right) \leqq \mathrm{g}\left(\mathrm{s}_{2}\right)$.

The principal determinant of the pattern of prices will be the distribution of these costs in the population of traders. We will allow for different distributions of costs within the four types of traders A+, A-, B+, B-. For example, let $\mathrm{h}_{\mathrm{A}+, \mathrm{s}}(\xi)$ be the distribution function of the costs of delay (acceleration) of $s$ days within the population of taxable buyers. That is,

$$
\mathrm{h}_{\mathrm{A}+, \mathrm{s}}(\xi)=\operatorname{prob}(\mathrm{g}(\mathrm{s}) \leqq \xi \text { for a taxable buyer })
$$

Similarly we define the distribution functions $h_{A-, s}(\cdot), h_{B+, s}(\cdot), h_{B-, s}(\cdot)$, for each date s.

\section{The Timing Decision}

The dividend wil1 be normalized to $\$ 1$ throughout our analysis. 
We consider now a single trader with a cost function $g(s)$. To make our analysis of his trading decision concrete, let us suppose that he is a taxable buyer (A+).

This individual is embedded in a system in which the path of expected prices around the ex-dividend day is known to be

$$
\cdots, p(-2), p(-1), p(0), p(+1), p(+2), \cdots
$$

The total cost of buying shares before the ex-dividend date is the price paid plus the cost of the timing decision, if any, minus the aftertax value of the dividend. If we are considering a date $t<0$ and the optimal trading date for the individual is $t$ ', we have

$$
p(t)+g\left(t-t^{\prime}\right)-(1-\bar{\theta}) \text { if } t<0
$$

On or after the ex-dividend date we have

$$
p(t)+g\left(t-t^{\prime}\right) \quad \text { if } t \geq 0 \text {. }
$$

The overall minimum cost of acquisition for a taxable buyer occurs on the date $t$ for which the lowest value of $(2)$ or $(3)$ is reached. On the basis of this calculation we can see how the investor will shift his purchase date from $t^{\prime}$ to $t$.

For taxable sellers and untaxed traders of either type, calculations precisely analagous to these can be made. A different pattern of shifting trades around the desired date would be implied.

\section{$\underline{\text { Equilibrium }}$}

We began by assuming that the desired purchase dates were uniformly distributed in the absence of taxation or dividends. The analysis above 
makes it clear that this uniformity cannot be expected of the actual trading dates when taxes and dividends are relevant.

If investors perceive that the price sequence will be $p=(\ldots p(-2)$, $p(-1), p(0), p(1), p(2), \ldots)$ then they may be induced to shift from their otherwise optimal trading date to some other date. The actual rate of arrival of orders to trade at date $t$ by taxable buyers is the sum of the arrival rates for optimal trades at $t^{\prime}$ multiplied by the probability that this investor will switch from $t^{\prime}$ to $t$.

Let these actual arrival rates be denoted $a_{A+}(t), a_{A-}(t), a_{B+}(t), a_{B-}(t)$. It is important to note that each rate depends upon $\mathrm{P}$ and is proportional to the corresponding undistorted arrival rate $\lambda$. The nature of the dependence is complex because it varies with the distributions of costs $h(\cdot)$ in the different populations of traders.

In an equilibrium we have the equality of the aggregate arrival rates of buyers' orders with those of sellers:

$$
a_{A+}(t)+a_{B+}(t)=a_{A-}(t)+a_{B-}(t)
$$

for all $\mathrm{t}$. 


\section{Equilibria in Various Special Cases}

\section{General Remarks}

Before examining the kinds of equilibria that are possible and the implications of each for the underlying questions of tax induced investor selfselection and firm valuation, a few general remarks are in order. The fall in stock prices on the ex-dividend date is well-documented. Questions concern whether it differs from one firm to another in a systematic manner related to tax considerations. Apart from the one-day drop in prices several investigators ${ }^{*}$ have considered the average yields over longer holding periods. Intervals containing the ex-dividend day and intervals entirely on one side or the other have been considered. The findings are tentative, but they do seem to reveal some systematic price fluctuation on days other than the exdividend day.

We will see below that our theory can accomodate such fluctuations; but they cannot be used to make inferences about the underlying questions of interest because one cannot identify the parameters of the relevant costs of delay and acceleration.

We now turn to some special cases of interest in which the basic issues can be discussed. First we take a model in which there is only delay and not acceleration. The equilibrium conditions will be weakened slightly to allow us to ignore all anticipated price fluctuations except those taking place on the ex-dividend date itself.

\section{Model I}

Here we assume that $p(t), t=0, \pm 1, \pm 2, \ldots$ has only two distinct values; it is constant before the ex-dividend date and from the ex-dividend date onward.

The most extensive analysis can be found in Black and Scholes (1973) who consider seven different strategies for round trip trading near the ex-dividend date for each of ten portfolios. Durand and May (1960) also present evidence for a two week interval around the dividend date, for AT\&T stock only. 
Let

$$
x=p(-1)-p(0)
$$

be the price drop in response to the $\$ 1$ dividend payment.

We want to allow delay but not acceleration of trades. Thus we assume $\mathrm{h}_{\mathrm{A}+, \mathrm{s}}(\xi)=\mathrm{h}_{\mathrm{A}-, \mathrm{s}}(\xi)=\mathrm{h}_{\mathrm{B}+, \mathrm{s}}(\xi)=\mathrm{h}_{\mathrm{B}-, \mathrm{s}}(\xi)=0$ for all $\mathrm{s}<0$ and all $\xi$. In this way costs of acceleration are effectively infinite for all groups.

Because the price sequence is assumed to have such a simple form, the only equilibrating variable being $x$, we must relax our equilibrium conditions slightly. Instead of requiring an exact, day-by-day, equality of arrival rates as in (4) we will say that $x$ is in equilibrium if the fraction of people who delay purchases from one side of the ex-dividend to the other equals the fraction of those who similarly delay sales.

The special form of $\mathrm{p}$ and the assumptions we have already made on $\mathrm{g}(\cdot)$ make it relatively easy to write this equilibrium condition explicitly. Any delay will come from taxable buyers (At) and untaxed sellers (B-). No one who delays will execute his trade before the ex-dividend date. Indeed all delayed trades will be executed on the ex-dividend date. Any further delay is costly because $\mathrm{p}(\cdot)$ is constant, and $\mathrm{g}(\cdot)$ is increasing.

Therefore equilibrium requires that

$$
\lambda_{\mathrm{A}+} \sum_{\mathrm{s}=1}^{\mathrm{S}} \mathrm{h}_{\mathrm{A}+, \mathrm{s}}(\mathrm{x}-(1-\bar{\theta}))=\lambda_{\mathrm{B}-\sum_{\mathrm{s}=1}}^{\mathrm{S}} \mathrm{h}_{\mathrm{B}-, \mathrm{s}}(1-\mathrm{x}) .
$$

where $S$ is a number sufficiently far in the past that $g(S)>\max (x-(1-\bar{\theta}), 1-x)$ for all traders.

Let $\mathrm{H}_{\mathrm{A}+}(\mathrm{x}-(1-\bar{\theta}))=\sum_{\mathrm{s}=1}^{\mathrm{S}} \mathrm{h}_{\mathrm{A}+, \mathrm{s}}(\mathrm{x}-(1-\bar{\theta}))$ and $\mathrm{H}_{\mathrm{B}-}(1-\mathrm{x})=\sum_{\mathrm{s}=1}^{\mathrm{S}} \mathrm{h}_{\mathrm{B}-, \mathrm{s}}(1-\mathrm{x})$. The equilibrium value of $x$ is determined completely by $\lambda_{A+}, \lambda_{B-}$ and these two functions. 
The comparative statics of $x$ are easily studied by examining (4) and noting that $\mathrm{H}_{\mathrm{A}+}(\cdot)$ and $\mathrm{H}_{\mathrm{B}-}(\cdot)$ are increasing functions. Therefore $\mathrm{x}$ is decreasing in $\lambda_{A+}$, increasing in $\lambda_{A-}$ and decreasing in $\bar{\theta}$. The more heavily trade is dominated by taxable traders, the more $x$ reflects their tax rate and is therefore smaller. The more heavily taxed the owners of the security are, the smaller the price drop per dollar of dividend.

Some special remarks are relevant to the treatment of capital gains taxes in the above analysis. We have used $1-\bar{\theta}$ to represent the ratio of the net of tax dividend yield to the net of tax capital gains yield. If more of the investors have a higher capital gains tax rate, the effective change in $1-\bar{\theta}$ is upward and $x$ should increase. In periods following an increase in the stock's price, more of the sellers are likely to be liable for capital gains taxation. Therefore, even in periods when the statutory tax rates are fixed the effective rate for our model will vary. It will be different from one investor to another ${ }^{*}$, and it will tend to be negatively related to the stock's current price compared with the past level at which purchases may have been made. ${ }^{* *}$

To summarize this discussion, it is fair to say that we have given a theory, though admittedly restrictive in its assumptions, which explains the price decline on ex-dividend days in an equilibrium model where investors have heterogenous tax rates. The qualitative behavior of the model seems sensible, and it is robust to generalizations such as more than two tax categories of investors, etc.

\footnotetext{
* See the empirical treatment of this problem below. **

The complexity of U.S. tax laws regarding carryover provisions and the offset rules relating short and long term gains and losses to ordinary income make it impossible to give a systematic quantitative treatment of this problem without longitudinal tax return data. Nevertheless in the next section we discuss an approximate method of dealing with it using only market data.
} 
We now turn to the question of whether $1-x$, as measured, can serve to represent the average tax rate applicable to the investors in the company. It is clear that the answer is, in general, no. Therefore we will try to examine the sources and directions of possible biases. Let the fraction of shares owned by the taxed and untaxed groups be $\alpha_{A}$ and $\alpha_{B}$ respectively.

Consider the case in which the costs of delay are identical from one group to another and the arrival rates for optimal trade dates $(\lambda)$ are proportional to share ownership $(\alpha)$. Further let us assume that the (common) $\mathrm{H}(\cdot)$ function is linear within the relevant range

$$
\mathrm{H}(\xi)=\beta \xi .
$$

Direct substitution into (4) implies that

$$
\mathbf{x}=1-\alpha \bar{\theta}
$$

This is one minus the weighted average of the tax rates for the two groups. Relaxing each of the assumptions under which the above result holds reveals the directions of possible bias. We take these one at a time.

$$
\text { 1. } \lambda_{\mathrm{A}+} / \lambda_{\mathrm{B}-}<\alpha / 1-\alpha
$$

This might reflect a lower propensity to trade among taxable investors than among the untaxed. Several factors might operate in this direction. Untaxed investors have no problems with "lock-in" effects due to capital gains taxation at realization. To the extent that they are large institutions such as pension funds they may have lower transaction costs. There is some evidence that the volume of trade due to "institutions" is greater than their share of stock ownership, but "institutions" are not all tax-exempt, as they 
include life insurance companies, banks trading for trust accounts and mutual funds, all of whom are taxed. I know of no direct evidence available on the proposition as stated, but there may be some reason to believe it.

This hypothesis would cause $\mathbf{x}$ to exceed $1-\alpha \bar{\theta}$. That 1 , $\mathbf{x}$ as measured would be biased towards one.

2. $\mathrm{H}_{\mathrm{A}+}(\xi)<\mathrm{H}_{\mathrm{B}-}(\xi)$

For reasons similar to those above, taxable investors, whose holding periods tend to be longer, might be less sensitive to relatively minor profit opportunities at the cost of some delay. Similarly, to the extent that they have less trading activity relative to their total wealth, they may have higher liquidity costs and therefore more reason not to deviate from their optimal trading dates. This difference in delay costs can be approximated in several ways. If

$$
\begin{aligned}
& \mathrm{H}_{\mathrm{A}+}(\xi)=\beta_{\mathrm{A}+}(\xi) \\
& \mathrm{H}_{\mathrm{B}-}(\xi)=\beta_{\mathrm{B}-}(\xi)
\end{aligned}
$$

where $\beta_{A+}<\beta_{B_{-}}$, then

$$
\mathbf{x}=1-\frac{\beta_{A}}{\beta_{B}-\alpha\left(\beta_{B}-\beta_{A t}\right)} \alpha \bar{\theta}>1-\alpha \bar{\theta} .
$$

Thus this effect, if present, will reinforce the trading frequency effect studied in 1 . above.

Similarly, a differential additive shift in $\mathrm{H}_{\mathrm{A}+}(\cdot)$ and $\mathrm{H}_{\mathrm{B}-}(\cdot)$ of the form 
(8)

$$
\mathrm{H}_{\mathrm{A}+}(\xi)=\mathrm{B}_{0}^{+}+B \xi
$$

$$
\mathrm{H}_{\mathrm{B}-}(\xi)=\mathrm{B}_{0}^{-}+B \xi
$$

with $\beta_{0}^{+}<\beta_{0}^{-}$would yield

$$
x=1-\alpha \bar{\theta}+\frac{\alpha\left(\beta_{0}^{-}-\beta_{0}^{+}\right)}{\beta}
$$

which again represents an upward bias.

\section{Nonlinearities in $\mathrm{H}(\cdot)$}

The assumption that $H(\cdot)$ is linear over the relevant range is, of course an approximation. The simplest modification to ( 6 ) would involve equal positive shifts and, as we saw in ( 8 ) would not give rise to any bias. While I see no compelling theoretical reason to suppose that $\mathrm{H}$ is either concave or convex, an argument for convexity can be made as follows, and it may be of interest to explore its implications for the bias in $x$.

Evidence for the postponement of trades is weak. ${ }^{*}$ Therefore we may suppose that the costs of delay are large for most people. If the distribution of delay costs for every delay interval is unimodal, $\mathrm{H}$ will be convex below the mean. If we take, for example,

$$
H(\xi)=\beta \xi+\gamma \xi^{2}
$$

with $\beta, \gamma>0$, it is possible to compute the equilibrium value for $x$. For moderate values of $\gamma$ the bias can go in either direction, and it tends to be smal1. However when $\gamma$ is large and $\beta$ is small $x$ approaches $1-\frac{1-\alpha+\alpha \bar{\theta}}{2-\alpha}$ which is less than $1-a \bar{\theta}$. Thus a very strong convexity of $\mathrm{H}$ may impart a bias in the opposite direction from those indicated above.

This of course means net delays over accelerations of trades. The latter are ruled out here by assumption, but see the next subsection: Model II. 


\section{Model II}

In this model we introduce the possibility that trading dates are accelerated as well as delayed. Costs of acceleration are allowed to differ from costs of delay. We will show that the presence of acceleration does not introduce a bias in the estimate of average tax rates under the maintained hypothesis that cumulative cost distributions can be linearly approximated and are the same across investor tax statuses.

We study such a model not merely for the sake of increased generality. In Section 6 evidence on the volume pattern around exdividend days will be presented. It will be shown that the delay-only model cannot be correct. Therefore it is necessary to examine a model whose equilibrium could be consistent with the observed trading volumes around ex-dividend days.

As in Model I we will assume that expected prices take a single downward jump on the ex-dividend date. Delay will be due exclusively to taxable buyers and untaxed sellers, and acceleration will be due to untaxed buyers and taxed sellers. In equilibrium the value of $x$ must equalize the net delay by buyers to that by sellers, where net delay is the excess of delay over acceleration.

A taxable seller whose optimal trade date is $s>0$ will accelerate his trade to $t=-1$ if

$$
g(s+1)<x-(1-\bar{\theta})
$$

And an untaxed buyer will accelerate if

$$
g(s+1)<1-x
$$

Net delay by buyers is thus 


$$
\lambda_{A+}{ }_{A+}(x-(1-\bar{\theta}))-\lambda_{B+}{ }_{B+}(1-x)
$$

and net delay be sellers is

$$
\lambda_{B-}{ }_{B-}(1-x)-\lambda_{A-}{ }_{A-}(x-(1-\bar{\theta}))
$$

where $\mathrm{H}_{\mathrm{B}+}(\cdot)$ and $\mathrm{H}_{\mathrm{A}-}(\cdot)$ are defined in an analagous manner to $\mathrm{H}_{\mathrm{A}+}(\cdot)$ and $\mathrm{H}_{\mathrm{B}_{-}}(\cdot)$. Using ( 1 ) the equilibrium condition becomes

$$
\begin{aligned}
\lambda_{\mathrm{A}+}\left(\mathrm{H}_{\mathrm{A}+}(\mathrm{x}-(1-\bar{\theta}))+\mathrm{H}_{\mathrm{A}-}(\mathrm{x}-(1-\bar{\theta}))\right) \\
=\lambda_{\mathrm{B}-}\left(\mathrm{H}_{\mathrm{B}-}(1-\mathrm{x})+\mathrm{H}_{\mathrm{B}+}(1-\mathrm{x})\right) .
\end{aligned}
$$

It is evident that this is qualitatively the same as ( 5 ). Let us investigate whether a bias in $\mathrm{x}$ results when delay costs differ from acceleration costs, but each is the same across the two tax groups. We continue to assume linearity in $H(\cdot)$. Thus for traders who delay we have

$$
\mathrm{H}_{\mathrm{A}+}(\xi)=\mathrm{H}_{\mathrm{B}_{-}}(\xi)=\beta^{\mathrm{d}} \xi
$$

and for those who accelerate trades:

$$
\mathrm{H}_{\mathrm{A}-}(\xi)=\mathrm{H}_{\mathrm{B}+}(\xi)=\beta^{\mathrm{a}} \xi
$$

Also maintain the unbiased trading propensity assumption that $\lambda=\alpha$ for grap. Equilibrium requires precisely the same condition as in the delay-only case: $x=1-\alpha \bar{\theta}$. Thus differential costs of acceleration and delay do not cause a bias in the value of $\mathrm{x}$ under these assumptions. 
Summary: Sources of bias in $x$ as a measure of $1-\alpha \bar{\theta}$

We have seen that there are several possible sources of bias in using the price drop on the ex-dividend date as a measure of the average effective dividend yield compared to the capital gains yield. The likely deviations from the unbiased case are:

1. Trading propensities $(\lambda)$ can differ from investor compositions $(\alpha)$, with untaxed investors.

2. Costs of delay and acceleration for taxable traders may exceed those for the untaxed.

3. Non-linearities in $\mathrm{H}$.

In both 1. and 2. the effect is to bias $x$ toward 1 . In 3 . the effect can go either way. Therefore, a finding that $x$ is significantly different from 1 is reinforced by our belief that 1 and 2 may be operative. Kalay's (1978) estimate that $x$ is not significantly different from 1 should be reassessed in this light as well. 
5. Empirical Measurement of Clientele Effect by $x$

The theoretical analysis of the last section can be summarized as follows: Biases in the use of $x$ to estimate the average tax rate may be present. However, under the hypothesis that relative costs of delay and acceleration across investor tax categories do not differ from one company to another, comparisons of $\mathrm{x}$ across companies can be used to detect the presence of clientele effects. Furthermore, the extent to which $\mathrm{x}$ is below unity can be ascribed to tax-induced preferences for capital gains as opposed to dividends.

In this section we present the results of an empirical investigation into these issues.

Roughly speaking, the theory tells us that

$$
\begin{aligned}
& P(0)-P(-1)=-\left\{\text { average effective }\left(\frac{1-\theta}{1-c}\right)\right\} \times D I V \\
& + \text { other variables unrelated to the dividend } \\
& + \text { error. }
\end{aligned}
$$

As an approximate correction for heteroscedasticity we assume that the error is proportional to $\mathrm{P}(-1)$, but is otherwise the same across companies.

The principal variables on which we focus are those that might "explain" the effective tax rate. We tried four explanatory variables:

i) $\frac{\text { DIV }}{P(-1)}$ the ratio of the quarterly dividend to price

ii) $\frac{\text { EARN }}{\mathrm{P}(-1)}$ quarterly earnings per share divided by price

iii) (1 - FRACINST) the fraction of investors classified as "noninstitutional"

iv) $T$ a synthetic variable designed to capture the taxation of capital gains at realization only, and the special tax rules that apply. This variable is discussed further below. 
The specification of the clientele effect is that the fraction of taxable traders is

$$
\alpha_{0}+\alpha_{1} \frac{\text { DIV }}{P}+\alpha_{2} \frac{\text { EARN }}{P}+\alpha_{3}(1-\text { FRAC INST })
$$

We expect $\alpha_{1}$ to be negative because taxable investors should be holding firms whose return, other things equal, will arise in the form of capital gains rather than dividends. The sign of $\alpha_{2}$ is ambiguous. To the extent that the "security" of the dividend is more important to taxable rather than untaxed investors, it would be positive. But this might well go the other way. Finally, $\alpha_{3}$ should be positive if our FRACINST variable is measuring anything that is not already picked up by the other variables.

The theory suggests that the average effective " $\frac{1-\theta}{1-c}$ is the weighted average of $T$ and 1 , with the weight on $T$ given by ( 9 ).

For "other variables" we used the performance of the Standard and Poors 500 stock index, in the form of its percentage change from the previous day's value. The idea is to capture market-wide information and related events. This variable is called MKT.

Thus we have

$$
\begin{aligned}
\frac{P(0)-P(-1)}{P(-1)} & =-\left\{\left[\alpha_{0}+\alpha_{1} \frac{D I V}{P}+\alpha_{2} \frac{\text { EARN }}{P}+\alpha_{3}(1-\text { FRACINST })\right] T\right. \\
+ & {\left.\left[1-\alpha_{0}-\alpha_{1} \frac{D I V}{P}-\alpha_{2} \frac{\text { EARN }}{P}-\alpha_{3}(1-\text { FRACINST })\right]\right\} \frac{D I V}{P} } \\
+ & \alpha_{4} \mathrm{MKT}+\varepsilon
\end{aligned}
$$


or

$$
\begin{gathered}
\frac{P(0)-P(-1)}{P(-1)}+\frac{D I V}{P}=\alpha_{0}(1-T) \frac{D I V}{P}+\alpha_{1}(1-T)\left(\frac{D I V}{P}\right)^{2}+\alpha_{2}(1-T) \text { EARN } \cdot \frac{D I V}{P} \\
+\alpha_{3}(1-T)(1-\text { FRAC INST }) \cdot \frac{\mathrm{DIV}}{P}+\alpha_{4} \text { MKT }+\varepsilon
\end{gathered}
$$

Equation (11) is our basic estimating equation.

The Data

Our data on price changes and dividends are observations on $29^{*}$ Dow-Jones companies from July 1962 - December 1977. These were selected from the CRISP tape. Data on earnings were taken from the COMPUSTAT file. FRACINST is taken from the Standard and Poor's Stock Guide.

The computation is made somewhat complicated by the fact that the CRISP tape lists distributions separately even though they may have occurred on the same day. ${ }^{* *}$ For example special dividends are often paid on the same day and to the same holders of record as ordinary dividends. The observed price change, of course, reflects the effects of both distributions. In each observation the value of $\frac{D I V}{P}$ is the actual dividend paid at that point in time. To the extent that dividends in different quarters are unequal, the proportion of taxable shareholders may reflect the average expected dividend yield rather than the actual payment at that date. Similarly, if there are lags in investors portfolio adjustments for tax reasons, a company that has just raised its dividend payment will have more taxable shareholders than the observed $\frac{\mathrm{DIV}}{\mathrm{P}}$ would predict. Therefore the aggregation of special dividends with ordinary quarterly dividends paid on the same date will "overcorrect" the underestimate of annual yield by $\frac{D I V}{P}$ in the other three quarters. For this reason we present two sets of regressions, one for "ordinary dividends only"

* Chrysler was deleted because of the irregularity of its dividepd. Including observations on Chrysler would have biased the results because $\frac{D I f}{P}$, when a dividend was paid, was not a good proxy for the anticipated long-term dividend yield. Thus (9) would have been misspecified. **

Previous authors who worked with this data did not state how they handled this problem. 
in which we deleted observations where more than one distribution occurred on the same day, and one for "all dividend distributions" in which the dividends are added together and treated as a single observation. There were only 36 such coincident distributions in the 15 year period that the data cover.

The results of the estimation of (11) are given in Tables 1,2 and 3 . The most striking result is the very strong significance of $\frac{D I V}{P}$ as a predictor of the effective average tax rate. The other predictors are of questionable significance.

The $\frac{\text { FARN }}{\mathrm{P}}$ variable is always insignificant. The behavior of $(1$ - FRACINST) is rather curious. Overall it has little effect. When the sample is divided Into two subperiods July '62 - December '70 and January '71 - December '77, this variable is very significant in each but with opposite signs. The institutions whose ownership is measured by this variable are quite heterogeneous in nature, including insurance companies, bank trust departments, pension funds and mutual funds. Some of these represent investors who are not taxed, while others, such as insurance companies, have complex tax rules which cause the "effective" $\frac{1-\theta}{1-c}$ to be sensitive to other components of their annual income even though the statutory tax rates are constant. It is possible that the behavior of this variable is affected by the uneven pattern with which different institutions acquired shares. However the estimated coefficients diverge so widely that such an explanation really does not suffice.

Several things should by observed.

1. Our theory suggests that the constant term should be suppressed. Over the whole sample period this specification is borne out. But again the two subperiods behave in a markedly different fashion.

2. The use of our synthetic tax variable had little impact. For each year we computed a weighted average realized return on Standard and Poors stock average over the previous five years. This was to reflect whether the 
typical seller had a capital gain to "protect". We then scaled a variable "c" so that it was equal to the statutory maximal capital gains rate when the largest gains had been experienced, and equal to zero when the largest average loss occurred. The variable $\theta$ was set equal to the statutory maximum tax rate on personal interest income. (Federal tax rates were used; taxation at the state level was ignored.) Our synthetic $\mathrm{T}$ was computed as $\frac{1-\theta}{1-c}$, as the theory suggests.

One might question why $c$ was computed on a market wide basis rather than separately for each security. The reason is that we imagine the active traders to be large ones. Their tax status in any year depends on their overall net longterm gains. Thus, for example, the effective capital gains tax on the marginal dollar of proceeds from selling a stock at a loss is the capital gains rate if he has taken other gains in the same year, but is closer to zero if the investor's net losses exceed the allowable maximum. Obviously, the crudeness of this calculation may be obscuring the true effects of tax rate fluctuations. Nevertheless we believe that this approach is faithful to the theory, and preferable to using similarly created "stock-by-stock" effective maximal tax rates.

3. The real goal of our exercise was to compute two quantities: The measured effective tax rate and the sensitivity of this rate to the firm's dividend policy. Tables 1,2 and 3 display these quantities for each equation. In the first of the two columns at the right we give the measured $\frac{1-\theta}{1-c}$ at the mean of the right-hand side variables:

$$
(1-\mathrm{T})\left\{\alpha_{0}+\alpha_{1} \frac{\mathrm{DIV}}{\mathrm{P}}+\alpha_{2} \frac{\text { EARN }}{\mathrm{P}}+\alpha_{3} \text { (1-FRACINST) }\right\}
$$

In the final column we show how this magnitude would vary when $\frac{D I V}{P}$ is increased by one 
standard deviation. For example, in Table 1 , the mean of the quarterly dividend divided by price was $.98 \%$ and 1 ts standard deviation was $.41 \%$. Thus these columns compare the measured $\frac{1-\theta}{1-c}$ for hypothetically identical stocks whose (ordinary) dividend yield varies from an annual rate of $3.92 \%$ to $5.56 \%$. Such a change Increases $\frac{1-\theta "}{1-c}$ roughly from .71 to .80 , the exact amount varying slightly with the specification.

This is rather strong evidence for the clientele effect. It is a stable relationship across subperiods despite the instability in the FRACINST coefficient. Indeed it does not vary with the specification except in those cases where a constant is included, and there it is completely irregular in behavior.

To correct for possible errors in the specification we also ran the same regressions as those reported in Tables 1, 2 and 3 including dumy vartables for each company. In general this had very little effect on the estimated effective tax rates or their sensitivity to dividend yields. Of the 29 dummy variables only five were significant at the $5 \% 1$ evel. These were DuPont and Texaco, with lower average returns and General Electric, United Technologies and Westinghouse with higher average returns. 


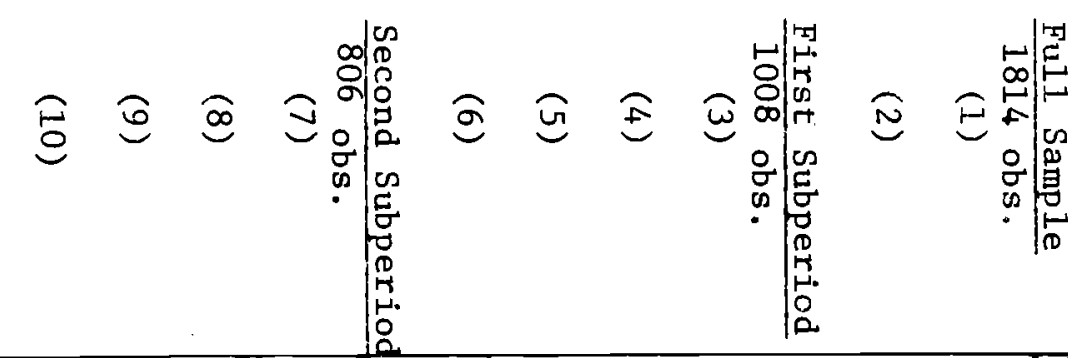

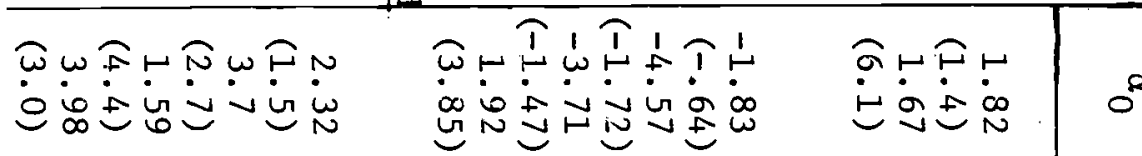

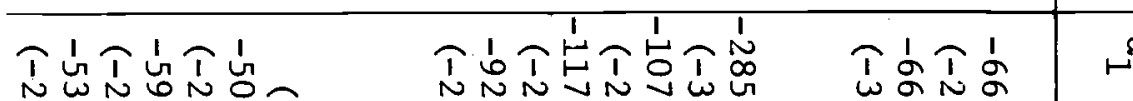

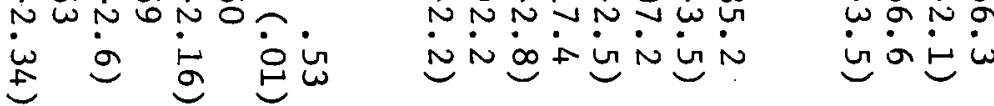

¿ $\quad$ e

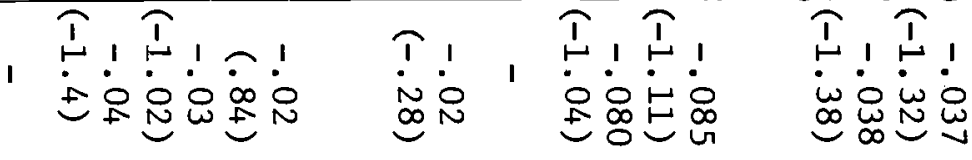

IN

i。

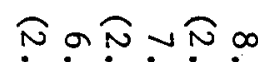

$\underbrace{-1}_{0}$

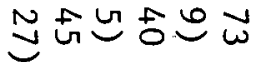

$1 \quad \dot{\omega} \dot{\omega}$

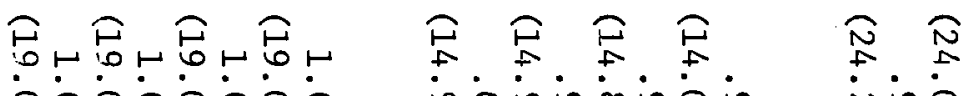

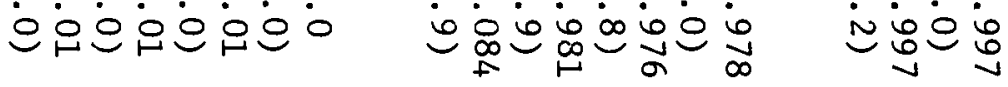

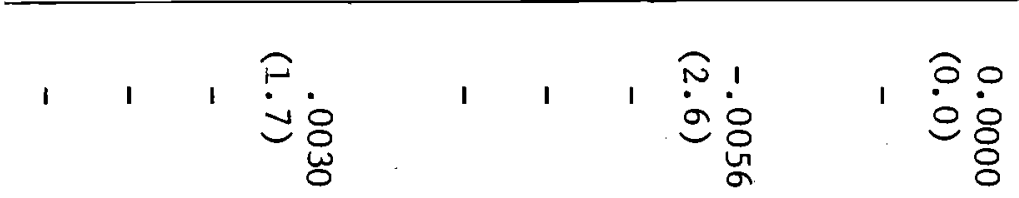

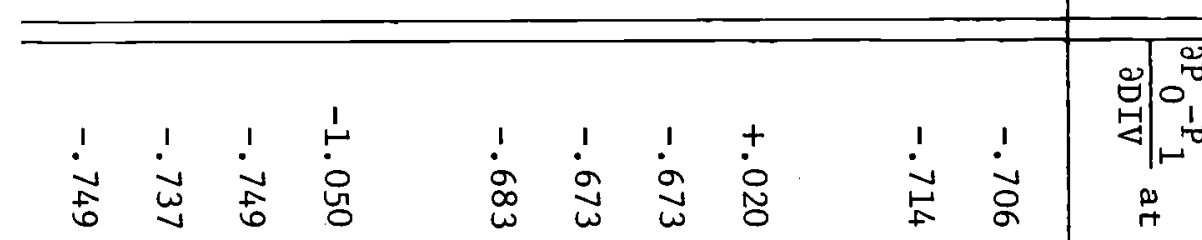

窇|

蕰

品.

吕

营

ก

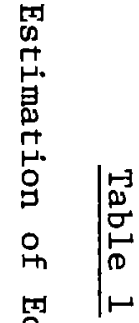

兵

9

蕰

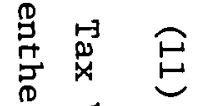

ח

最

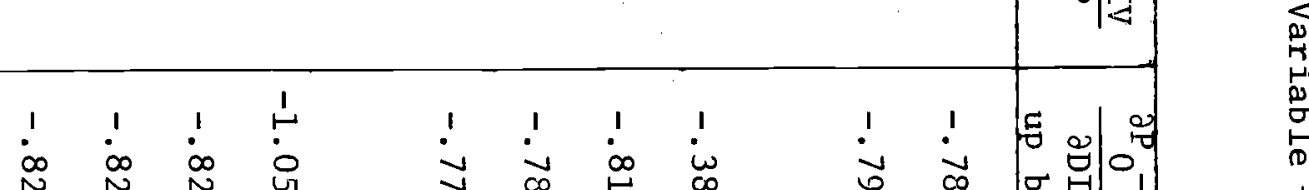

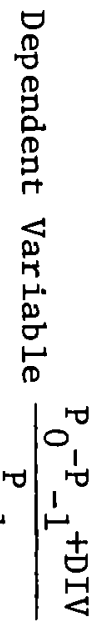




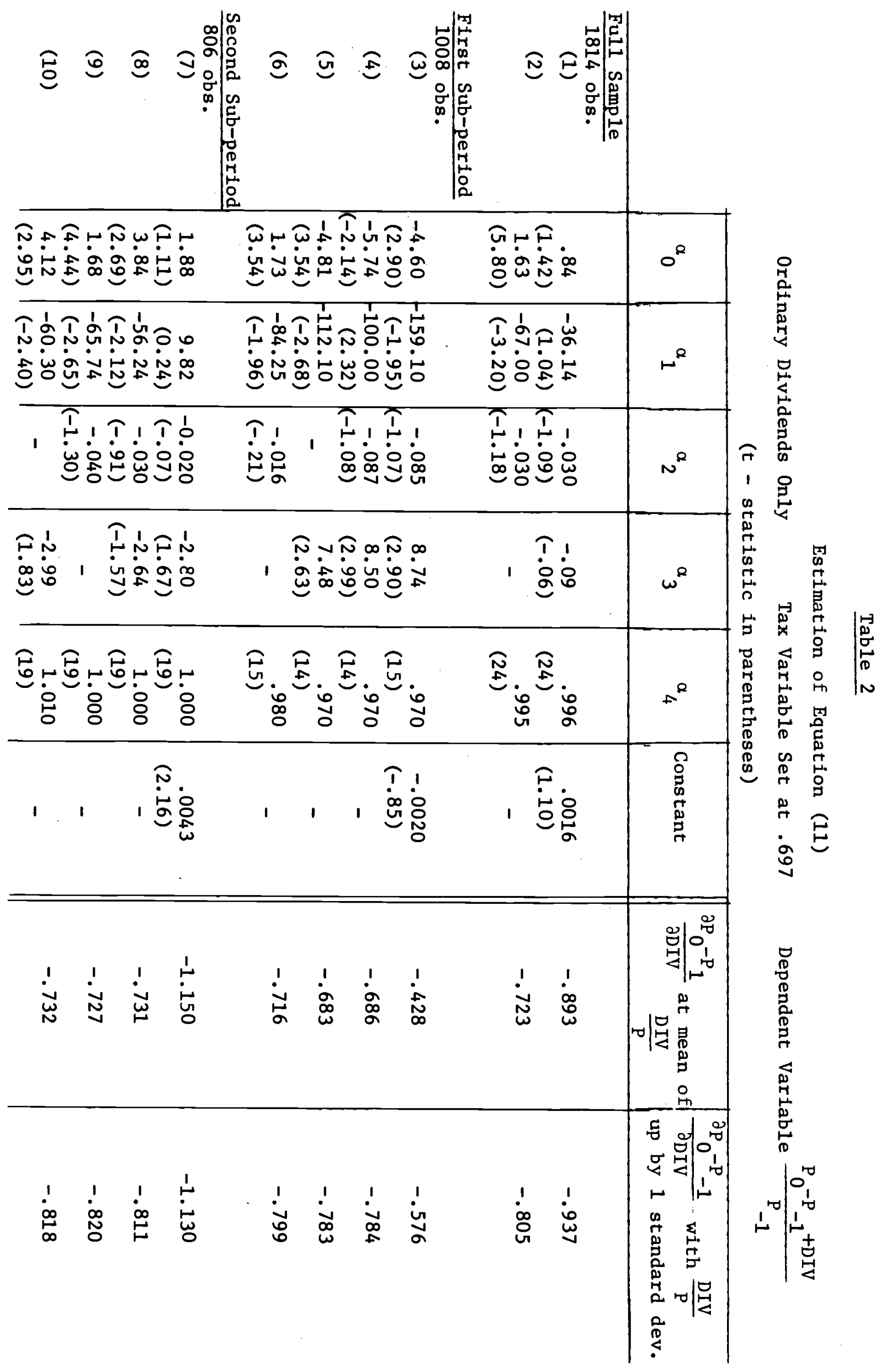




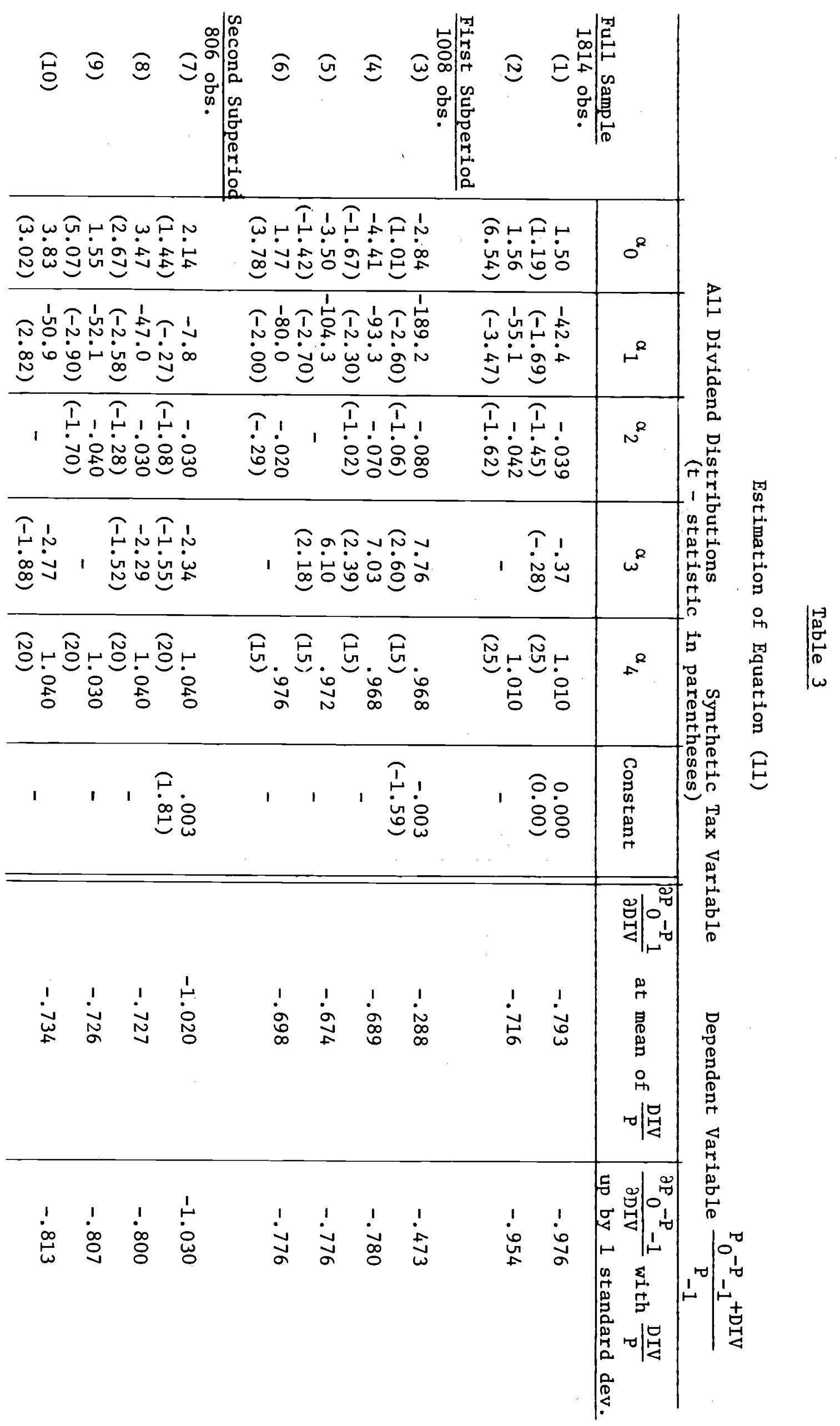




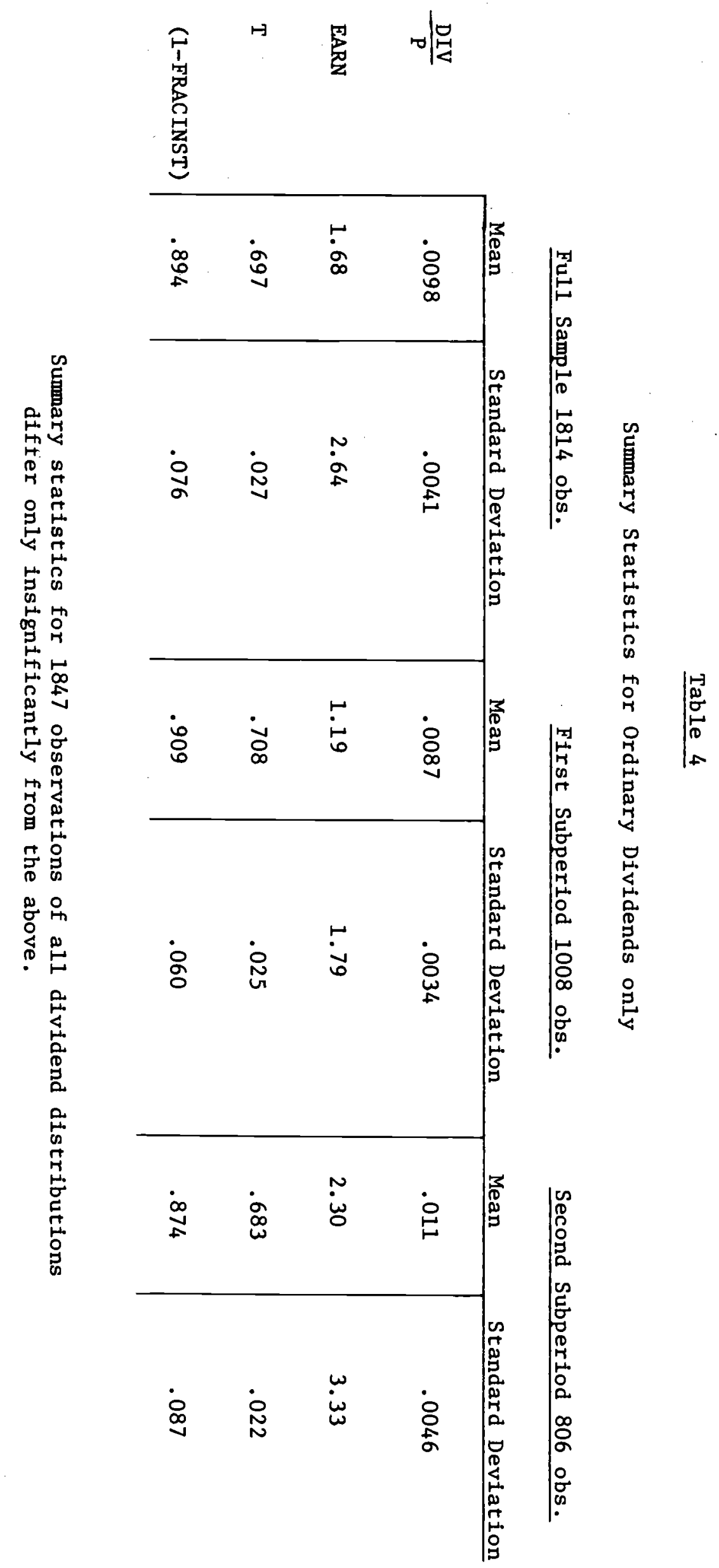


Comparison with Other Results

Three previous studies are similar to this one.* E1ton and Gruber (1970) used a sample of all NYSE traded stocks with positive volume on days before and after the ex-dividend date in the period April 1, 1966 - March 31, 1967. They had 4148 observations. Kalay (1978) used a subsample of 2540 of these but does not state how the sample was drawn. Elton and Gruber find strong evidence for a clientele effect while Kalay does not. Both studies fail to recognize that this period was one of high share prices which made capital gains rates higher than usual and would have biased $\frac{1-\theta}{1-c}$ toward one.

Black and Scholes (1973) use a much more extensive data set consisting of 36152 observations on a11 NYSE stocks in the period July 2, 1962 - December 30, 1970. They note significant differences between the clientele effects as measured over separate six month intervals within this period, but they do not attempt to attribute these differences to variations in the effective capital gains rate.

The most important difference between these data sets and ours is our concentration on the Dow Jones stocks. By using all securities on the NYSE and weighting all observations equally, much of the evidence is based on thinly traded issues where trades take place for reasons quite unrelated to the dividend. Kalay and Black-Scholes attempt to correct for some of the problems with thinly traded issues by modelling the "true" post-closing ex-dividend price on the day before the ex-dividend date. But this is only a part of the problem. We preferred to take a set of securities that are always actively traded and about which information is widely disseminated and actively sought.

* Other relevant references with different basic approaches are Barker (1959), Campbel1 and Beranek (1955), Durand and May (1960) and Readett (1956). 
The availability of 15 years of data, giving us over 1800 observations made the estimation feasible, and, we belleve, more accurate than the previous studies despite the somewhat smaller sample size. 
6. Evidence on the Pattern of Volume of Trade Around Ex-Dividend Days

Both Model I and Model II have implications for the pattern of trading volume. We therefore have made a separate study of this question. The results are reported in this section.

Even the most cursory glance at the volume of trade reveals the volatility and apparent unpredictability of these data. Our model would suggest that there are three determinants of trading volume: general "news" or the resolution of uncertainties not specific to the company, company-specific events not connected with the payment of dividends, and dividends, either in the recent past or in the near future.

The persistence of disturbances in volume is equally evident. Individual investors do not continually hold the market portfolio, nor do they hold on to a fixed portfolio whose mean and variance approximates that of the market portfolio. It seems to me that there is prima facie evidence that expectations are heterogenous and that investors hold what they believe will dominate the market portfolio on average. Moreover, the persistence of volume can be taken as an indication that individuals do not believe in the extreme version of the efficient markets hypothesis -- or else that there are so many "insiders" that one wonders who the "outsiders" must be. In any case, whatever the true portfolio theory model might be, we must allow for autocorrelation of errors in equations designed to predict volume.

\section{Estimating Volume for Each Company}

For each of the Dow Jones stocks one could imagine estimating the following regression: 
$\log$ vol $=$ Const + Time + Log mkt.vol $+E$

The idea is that "general information" shows up in the volume of the 28 other companies, mkt.vol, and to the extent that this causes trade in the stock in question mkt.vol will proportionately influence vol. Because companies differ in how closely they are related to the market, one would expect this constant-of-proportionality to vary, and it does so significantly. The presence of time in the equation is to capture the secular increase or decrease in the trading of this stock compared with the other Dow Jones companies taken together. The error term, $\varepsilon$, is assumed to follow a first-order autoregressive process.

There would be a problem with this autocorrelation correction precisely because of the fact that systematic fluctuations in volume around the exdividend day would be picked up by the autocorrelation parameter. This would bias the estimated coefficients and lead to incorrect results when we try to analyze the residuals of this equation on a daily basis.

To overcome this difficulty we excluded from the data base a seven trading day sequence around the ex-dividend date -- from $t=-3$ to $t=+3$. For each company the data consists of a collection of intervals between $t=+4$ for one dividend and $t=-4$ for the next dividend. The volume data we have come from the DRISEC data base of Data Resources, Inc. They cover the time period January 1, 1968 - December 31, 1977.

The companies in our sample paid around 40 quarterly dividends in this interval. All distributions other than regular quarterly dividends were ignored, for reasons that will be apparent shortly. Between each quarterly dividend there 
are about 71 trading days. As 7 of these are eliminated, there are, in all about 64 trading days in each sequence. Thus the data for each company are roughly 40 continuous sequences of 64 days each. The basic equation is estimated by pooling these sequences .

When one does this, however, there is a danger that systematic variations in volume over the quarterly cycle that are not accounted for in the estimating equation, might bias the coefficients. Examples of possible omitted variables include dates at which earnings of companies in related industries are announced, days on which various periodic government announcements are made, tax dates, holidays, etc. Because every company is different in these regards, it would be impossible and misleading to try to uncover the true causes of such systematic fluctuations for all of them.

To account for these possibilities we introduced four cyclical variables: $\sin \frac{\mathrm{t} \pi}{32}, \sin \frac{\mathrm{t} \pi}{16}, \cos \frac{\mathrm{t} \pi}{32}, \cos \frac{\mathrm{t} \pi}{16}$, allowing for periodicities equal to the quarterly cycle and equal to half the quarterly cycle. By combining these, considerable flexibility in the form of allowable cyclic behavior could be achieved.

In addition we use two dummy variables for specific days: the day on which the dividend is announced, and the day after that. This announcement date precedes the payment of the dividend by 5 - 10 days in most cases. Often, other information relevant to the company's earnings is announced at the same time. The day after the announcement date also could have special properties. Time zone differences between New York and the corporate headquarters can make this date the first one which is really relevant for announcement-induced 
trades. Or, more simply, delays in learning the news may create enough of a time lag so that the trade may not be executed until the following day.

Holidays and weekends must be accomodated somehow. We followed the rather straightforward approach of deleting them and treating Monday as directly following Friday for the purpose of autocorrelation. A practical matter of some importance in this data is that in 1968-1969 there were about 20 consecutive Wednesdays on which the exchange was closed due to massive paperwork backlogs. As these are not officially "holidays," they had to be deleted by hand from our sample. Here also, we assume that Tuesday and Thursday are adjacent, with the same autocorrelation parameter operative as between any other days.

\section{$\underline{\text { Results }}$}

The resulting parameter estimates are shown in Table 5. These equations explain some of the volume fluctuation, but many of the variables discussed above are generally insignificant. Typically, only the mkt.vol and the autocorrelation correction have real predictive content.

Our procedure was to use these estimated relations to project a "predicted volume" for each of the seven trading days in between the end of one quarterly cycle and the start of the next. Then the residuals of these relations are summed over all the quarterly cycles separately for each day in this seven day interval.

To assess whether delay or acceleration of trades is the rule, we group together the three days before the ex-dividend date $t=-3,-2,-1$ and the four days on and after it $t=0,+1,+2,+3$. For each of the 29 companies we divided the average of these residuals by the standard deviation that that 
average would have under the hypothesis that they were residuals from a correctly specified regression with the given standard error.

For example, take Allied Chemical on the 3 days preceding the dividend. The average of the 120 ( $=3$ days $\times 40$ dividends) residuals is $=.1806$. The standard error of the Allied Chemical regression is .565. Therefore, under the hypothesis that each residual is an independent drawing from a distribution with mean zero and this standard deviation, the standard error of the average would be .0516 . Thus, Allied Chemical has on average $3.5\left(=\frac{.1806}{.0516}\right)$ standard deviations less volume on these 3 days than would be predicted under the no-delay no-acceleration hypothesis.

The results of these calculations are displayed in Table 6. Before discussing these results, some additional comments are in order.

The sample size for each company is quite large. Therefore it is appropriate to neglect uncertainty about the standard error of the regression in performing these calculations. There is a problem, however, in using this standard error to represent the error in forecasting several days into the interval because of the autocorrelation correction. We look at the residual of the estimating equation on $t=-4$ and then apply the autocorrelation parameter successively on each of the following days to get the predicted value used above. Thus these projected values are not based on the same exogenous variables as the prediction equations and the standard error of the errors in these projections is understated.

To examine the extent of this error we look at the standard error of the estimating equation without correcting for autocorrelation at all. In the case of Allied Chemical it was .6127. Thus an upper bound on the standard error of the average 
deviation over the 3 pre-dividend days is .0559 . This upper bound is a better approximation to the true error for the 4 post-dividend days than for the predividend days. We will see below that this error in estimating the standard error under the null hypothesis cannot explain the divergence of our results from what would be observed if there were no dividend-induced changes in trading dates.

Turning to Table 6 we see that there are several salient features of these residuals. The variance of the pre-dividend residuals is much greater than that of the post-dividend residuals, even though, as noted above, the standard error of the regression is more severely underestimated for the latter than for the former. This indicates that the divergence from expected volume experienced before the dividend does not necessarily show up in the opposite bias after the dividend. The two level dectsion process that we have used to set up the theoretical model in Sections 2 and 3 is indirectly challenged by this finding. However it may be that the timing decision is varied by more than the three or four days implicitly assumed when we selected the interval from $t=-3$ to $t=+3$ for our study.

Another thing to note is the obvious non-normality of these residuals, despite the fact that each is already an average of 120 - 160 errors from the prediction equation. There must be other factors operating, particularly in the days just before the dividend, which vary from company to company.

We compared the companies with unusually large volume deviations to those that displayed atypical price behavior as evidenced by the coefficients in the dummy variable regressions discussed at the end of Section 5. However there was no particular colncidence among them. We were unable to discover anything via this route which might point to a potential for bias in the estimate of the 
effective tax rates.

The overall level and pattern of these residuals would point to two facts. The period around the ex-dividend date is quieter than one would expect, even after correction for the cyclical pattern of volume has been made. And acceleration of trades, rather than delay, seems prevalent.

These conclusions are heavily influenced by large residuals for several companies. The analysis of errors in the absence of normality has lead statisticians to employ what are called "robust" methods. The idea is not to let the thick tails of the underlying distribution have an undue influence on the estimate. One such method is to truncate any observations that are outside a fixed deviation from the sample mean down to this upper bound level. We employed a variety of such methods and the results were largely unaffected. Acceleration, on average, is more important than delay. Actual volume after the ex-dividend date is surely below its predicted level even allowing for the underestimation of standard errors discussed above. Before it, volume is close to that predicted, the precise estimate depending on the truncation point used.

The incompleteness of our specification has doubtlessly hidden many company-specific effects. Nevertheless the fact that volume patterns around ex-dividend days are atypical is very apparent. We must, therefore be suspicious that the composition of investors who are executing trades on these dates is not the cross-section of all the company's stockholders. This fact is perhaps a much more severe source of potential bias than asymmetries in delay and acceleration costs across tax categories. In conclusion, therefore, this study of trading volume reinforces our theoretically based conclusions that the observed price drop per dollar of dividend cannot be used to measure effective tax rates but can be used to indicate the presence of clientele effects. 


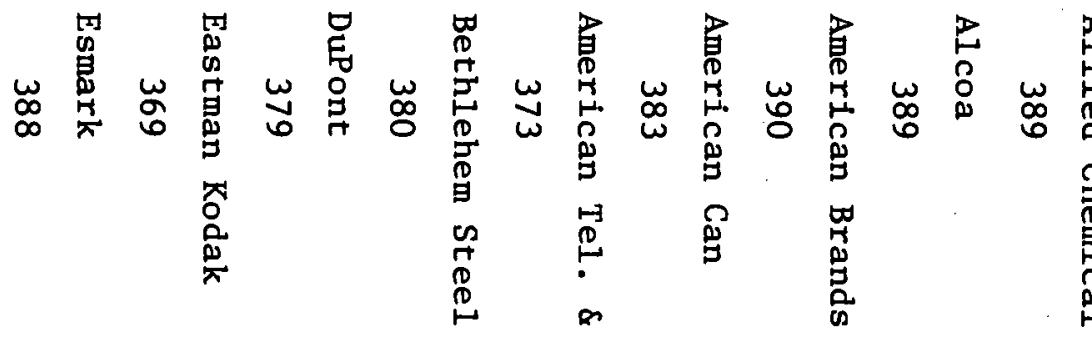

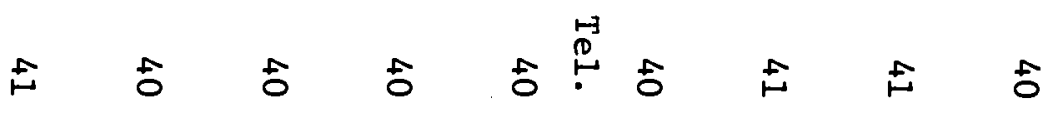

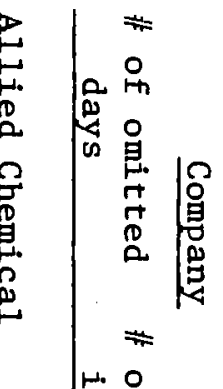

\%

要

$\frac{1}{4}$

这

is

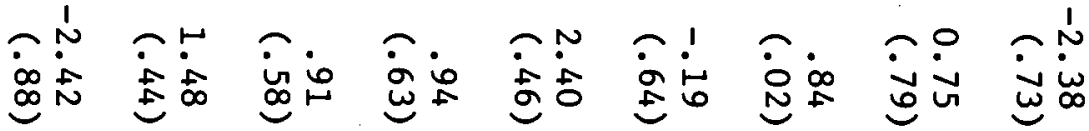

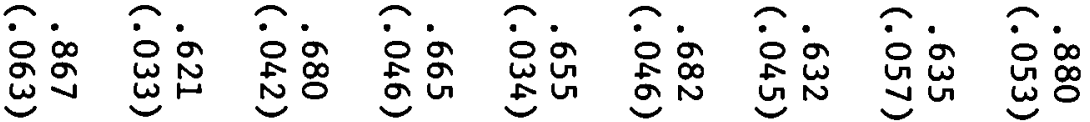

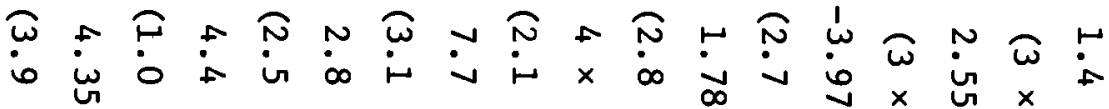

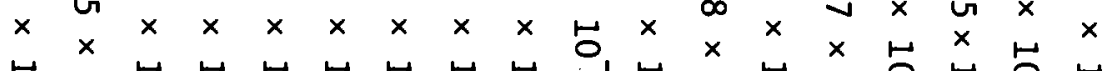

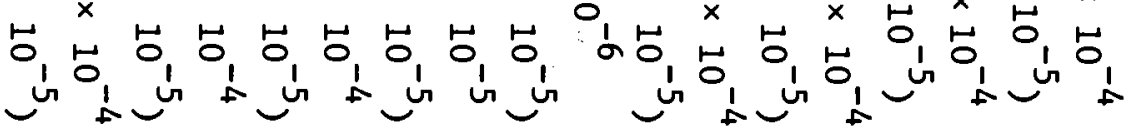

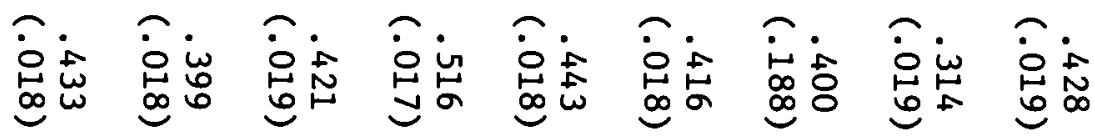

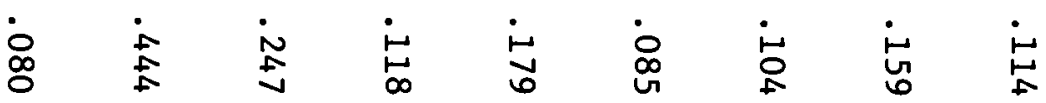

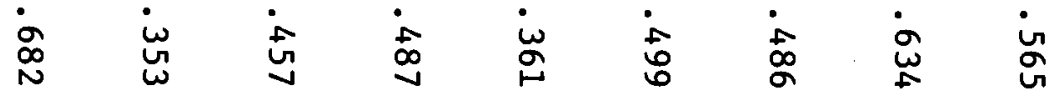




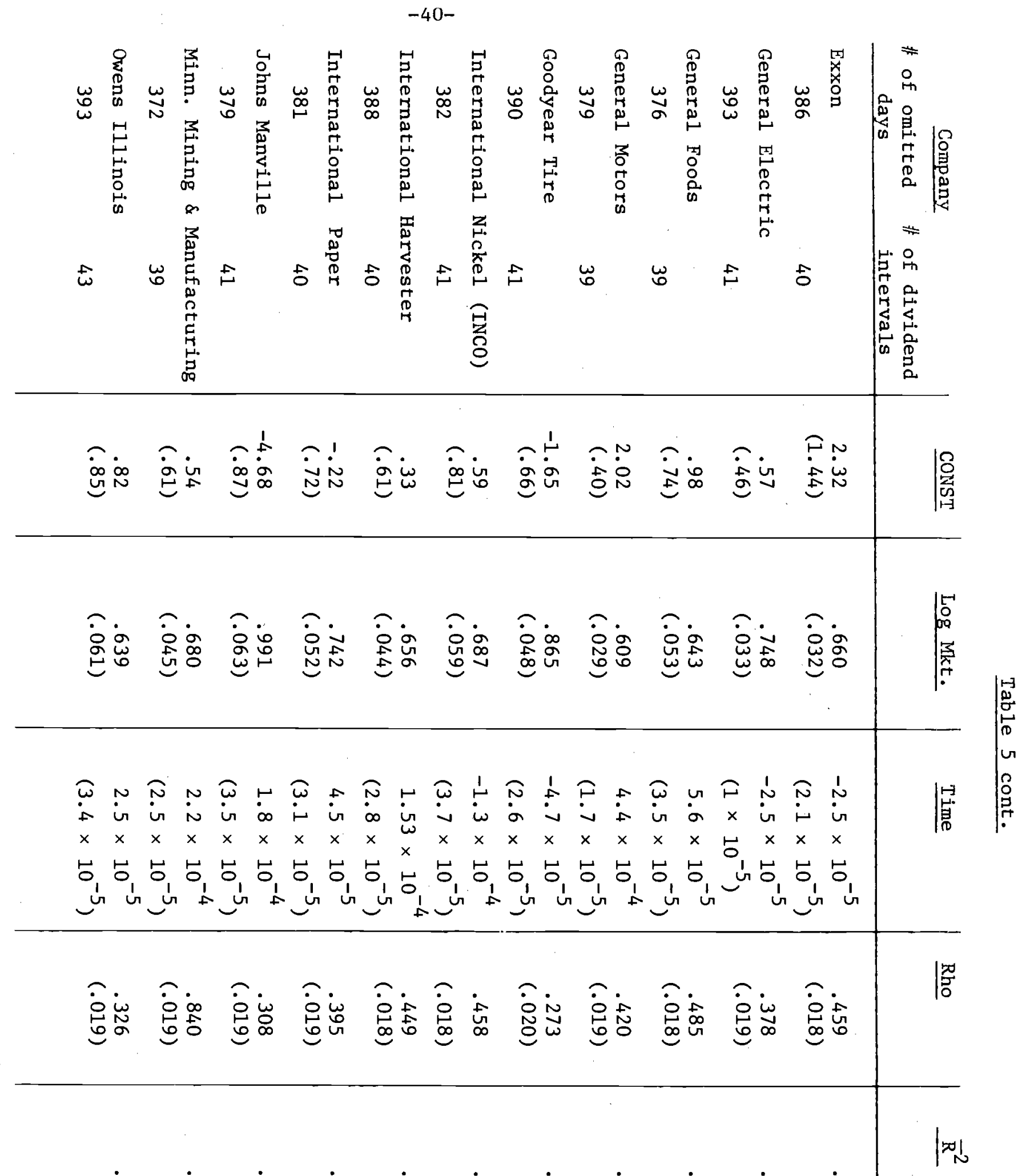

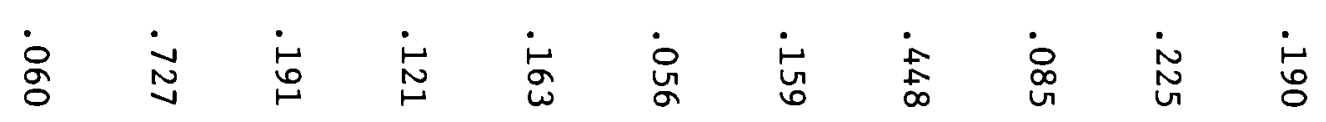

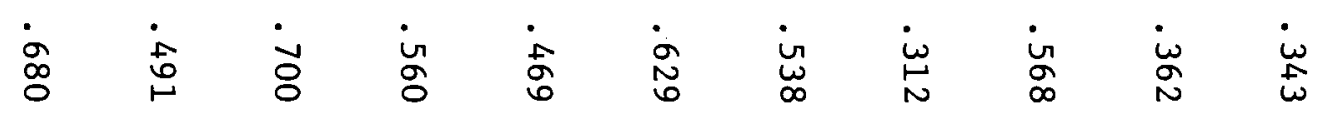




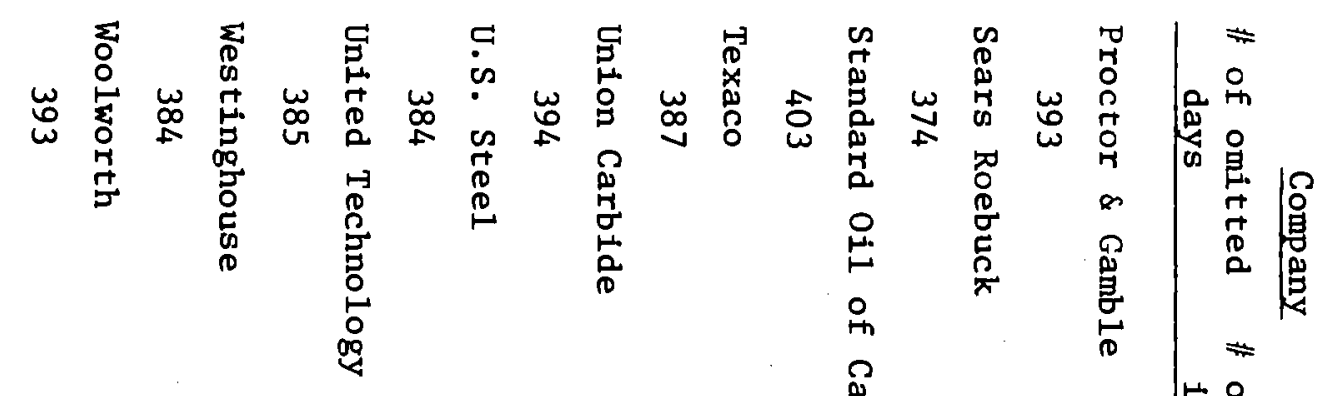
N 5 ث

붓

ஜ்

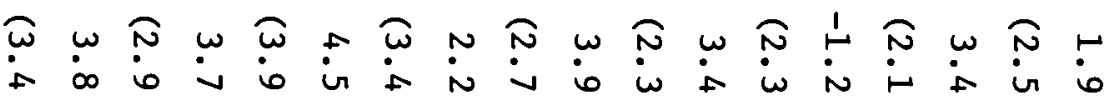

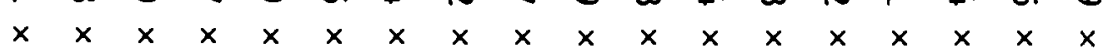

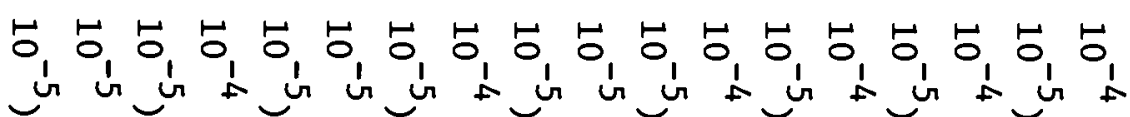

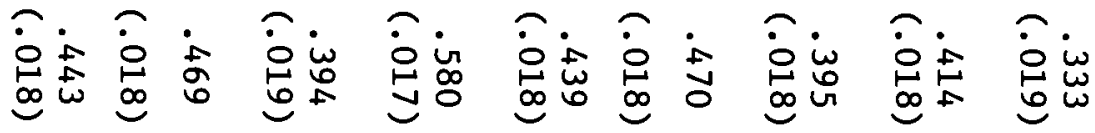

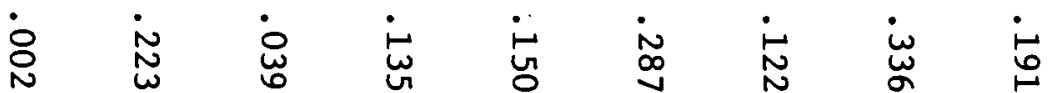

$|\pi|$

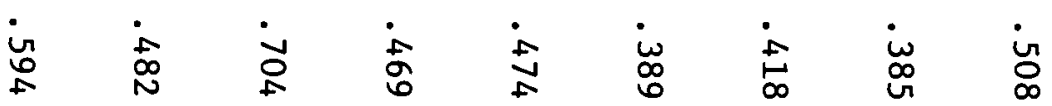


Table 6

Average Actual Log Volume - Predicted Log Volume Adjusted for Standard Error of Regression

\begin{tabular}{|c|c|c|}
\hline Company & 3 Pre-Dividend Days & $\begin{array}{l}\text { Ex-dividend Date and } \\
3 \text { Following Days }\end{array}$ \\
\hline A1lied Chemical & -3.50 & -0.31 \\
\hline Alcoa & -0.41 & +0.35 \\
\hline American Brands & +4.66 & +1.19 \\
\hline American Can Co. & -6.39 & -5.27 \\
\hline American Te1.\&Te1. & +3.12 & -0.26 \\
\hline Bethlehem Stee1 & +0.93 & -2.02 \\
\hline DuPont & -1.39 & -0.01 \\
\hline Eastman Kodak & -6.47 & -19.75 \\
\hline Esmark & +4.51 & -0.68 \\
\hline Exxon & -0.95 & -0.01 \\
\hline General Electric & -1.04 & +0.95 \\
\hline General Foods & -12.59 & -1.75 \\
\hline Genera1 Motors & +2.14 & +0.77 \\
\hline Goodyear Tire & +2.44 & +0.71 \\
\hline INCO & -2.55 & -2.40 \\
\hline Int. Harvester & +2.28 & +0.33 \\
\hline Int. Paper & +1.32 & +0.69 \\
\hline Johns Manville & -0.33 & -0.48 \\
\hline $\begin{array}{l}\text { Minn. Mining } \$ \\
\text { Manufacturing }\end{array}$ & +0.32 & -0.60 \\
\hline Owens-Illinois & -0.41 & +1.56 \\
\hline Proctor \& Gamble & -0.01 & +0.52 \\
\hline Sears & +1.82 & -1.27 \\
\hline $\begin{array}{l}\text { Standard } 0 i 1 \\
\text { of California }\end{array}$ & +1.17 & -1.71 \\
\hline Texaco & +2.26 & +1.09 \\
\hline Union Carbide & -1.28 & -0.61 \\
\hline U.S. Stee1 & +3.26 & +0.35 \\
\hline United Tech. & +2.33 & -0.42 \\
\hline Westinghouse & +1.04 & +6.79 \\
\hline Woolworth & +0.04 & -0.78 \\
\hline TOTALS: & -3.68 & -23.03 \\
\hline
\end{tabular}


$\underline{\text { References }}$

Auerbach, A. J. (1979), "Wealth Maximization and the Cost of Capital," Quarterly Journal of Economics, August, in press.

Barker, C. A. (1959), "Price Changes of Stock Dividend at Ex-Dividend Dates," Journal of Finance, 14, September.

Black, F. and Scholes M. (1973), "The Behavior of Security Returns Around ExDividend Days," unpublished paper, April.

Bradford, D. F. (1979), "The Incidence and Allocation Effects of Tax on Corporate Distributions," National Bureau of Economic Research, Working Paper No. 349, May.

Bradford, D. F. and R. H. Gordon (1979), "Taxation and the Stock Market Valuation of Capital Gains and Dividends: Theory and Empirical Results," National Bureau of Economic Research, Working Paper No. 409, November.

Campbell, J. A. and W. Beranek (1955), "Stock Price Behavior on Ex-Dividend Dates," Journal of Finance, 10, December.

Durand, D. and A. M. May (1960), "The Ex-Dividend Behavior of American Telephone and Telegraph Stocks," Journal of Finance, 15, March.

Elton, E. J. and M. J. Gruber (1970), "Marginal Stockholders Tax Rates and the Clientele Effect," Review of Economics and Statistics, 52, February.

Kalay, A. (1978), "The Ex-Dividend Day Behavior of Stock Prices: A Re-Examination of the Clientele Effect," Salomon Brothers Center for the Study of Financial Institutions, New York University, Working Paper No. 147, July.

King, M. A. (1977), Public Policy and the Corporation (Chapman and Hall: London, Halstead Press, New York).

Readett, P. B., Jr. (1956), "The Price Behavior of Stocks on Their Ex-Dividend Dates," S.M. Thesis, MIT. 